\title{
Image Case: Diffuse Bowel Polyposis during Childhood
}

\author{
Mohamad H. Emara', Mohamad I Radwan ${ }^{1}$, Hosam A Shoker \\ ${ }^{I}$ Tropical Medicine Department, Faculty of Medicine, Zagazig University, Egypt. \\ 2 Biala Fever Hospital, Kafr Elshikh Health Board, Egypt . \\ emara_20007@yahoo.com
}

This eight years old female child that presented by long history of anemia and passage of fleshy tissues per anus. She was examined locally by surgeon and there was no local cause for tissue passage. On examination she was pale and showed brown pigmentations of the mucous membrane in the lower lip and cheeks and also the tongue (Figure 1 and 2). We decided to examine her by colonoscopy and there were large sized polyps (Figure 3 and 4) involving the caecum, ascending and

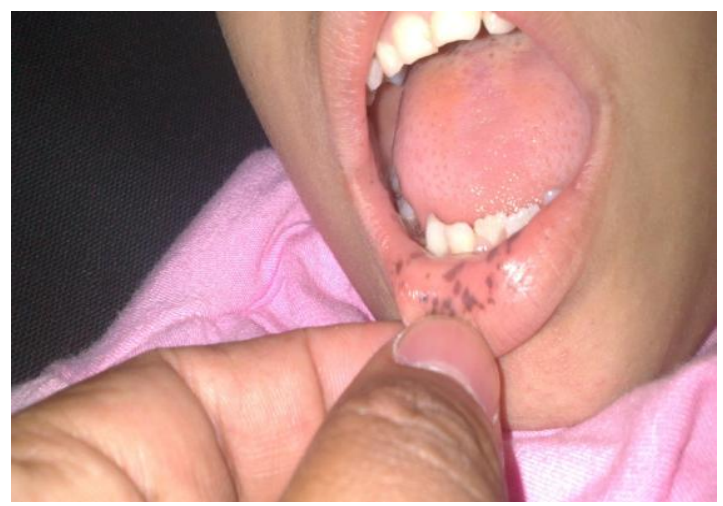

Figure (1): Pigmentations along the inner aspect of lower lip

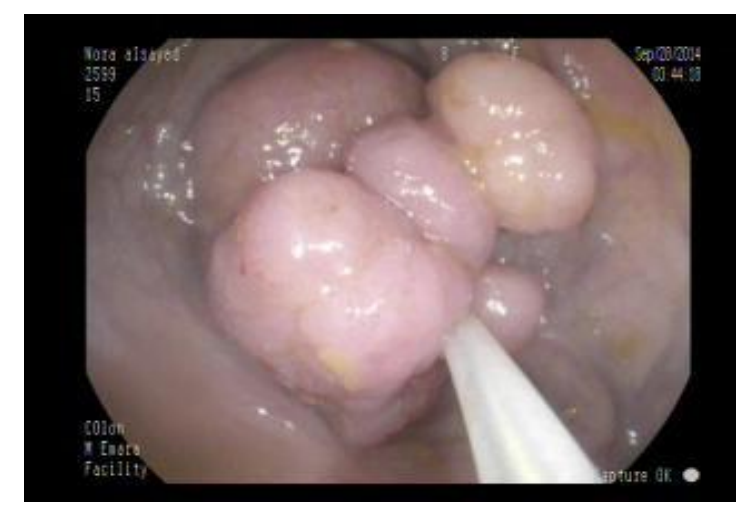

Figure (3): Large polyp (snared) in the ascending colon sigmoid colon that was successfully snared and hisopathological examination described villous adenoma. Later we examined her by upper endoscopy and surprisingly showed variable sized polpyps involving the gastric corpus, antrum and also the duodenum and upper jeujenum, histopathological examination of the gastric polyps showed also villous adenoma. The polyps and pigmentation raised the probability of Peutz-Jeghers syndrome.

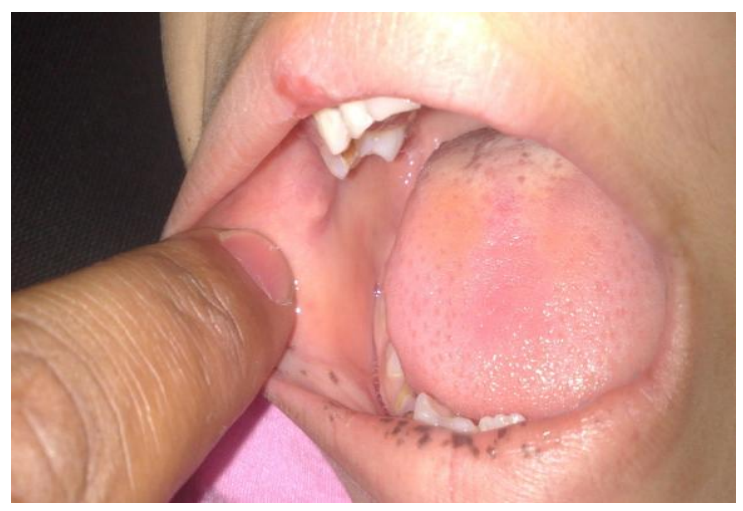

Figure (2): Pigmentations along the inner aspect of the cheek and tongue

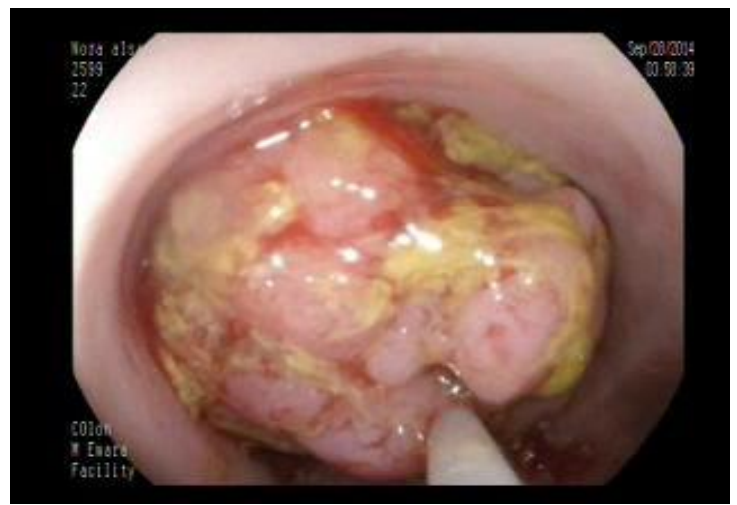

Figure (4): Extraction of snared large polyp from the sigmoid colon 